\title{
SEGURIDAD SOCIAL, DERECHO Y RELACIONES INTERNACIONALES EN MAGALLANES“
}

\author{
MARCELLO SASSO FUENTES"
}

\section{RESUMEN}

Este trabajo analiza el Convenio de Seguridad Social, celebrado entre las Repúblicas de Chile y Argentina, en 1971, en el marco del desarrollo del Derecho Internacional de los Derechos Humanos, y destaca su importancia para los trabajadores de Magallanes.

PALABRAS CLAVES: Seguridad Social, derecho, trabajadores de Magallanes.

\section{SOCIAL SECURITY, LAW AND INTERNATIONAL RELATIONS IN MAGALLANES}

\begin{abstract}
This work analyzes the Covenant of Social Security, celebrated between the Republics of Chile and Argentina, in 1971, in relation to the development of the International Law of the Human rights, and emphasizes its importance for the workers of Magallanes.
\end{abstract}

KEY WORDS: Social Security, Law, Magellan workers

\section{INTRODUCCIÓN}

El desarrollo de los modernos Estados nacionales, y sus ordenamientos jurídicos de base territorial, tiene un origen histórico determinado ${ }^{1}$. Esta premisa tan obvia nos permite plantear el tema de la revisión crítica de un esquema de Seguridad Social de base nacional y estatal, desde el punto de vista de las relaciones internacionales y considerando el carácter ideológico de una cierta noción sobre el Estado que tiende a ser prevaleciente en la actualidad.

Por ello, este artículo toma en cuenta la perspectiva de las relaciones internacionales, por una parte, y la noción misma de Estado que predomina en la actual coyuntura histórica, por la otra, como dos hitos referenciales de un intento de revisión crítica del rol del Estado en materia de Seguridad Social.

* El texto corresponde a una versión revisada de la ponencia presentada por el autor en el Congreso Internacional: "100 años de la Ley de Habitaciones Obreras: Pasado, presente y futuro del Derecho Laboral y de la Seguridad Social", organizado por la Facultad de Derecho de la Universidad de Chile, en el mes de octubre de 2006.

* Profesor Carrera de Derecho, Facultad de Ciencias Económicas y Jurídicas, Universidad de Magallanes, Av. Bulnes 01855, Punta Arenas, Chile.

1 Vid. Fioravanti, Maurizio (ed.), Lo Stato moderno in Europa. Instituzioni e diritto (Roma-Bari, Editori Laterza, 2004). 
A partir de lo anterior, se concluye con un análisis del origen y aplicación práctica, especialmente en la Región de Magallanes, del Convenio Chileno-Argentino de Seguridad Social, suscrito el año 1971, en adelante el Convenio ${ }^{2}$.

\section{LAS RELACIONES INTERNACIONALES}

En cuanto a las relaciones internacionales, esta perspectiva considera que ellas están constituidas no sólo por los vínculos entre Estados, sino que también por la interacción entre el conjunto de los actores internacionales de la más diversa clase, y por la protección que reciben las personas en el orden internacional ${ }^{3}$.

Por cierto, tal perspectiva de las relaciones internacionales no es nueva sino que responde a una larga reflexión teórica que arranca del ilustre Hugo Grocio (1583-1645), quien, ya en los albores de los Estados Modernos, en la primera mitad del siglo XVII, planteó, a través de su original relectura de un texto clásico romano sobre el ius gentium ${ }^{4}$, la

2 El Convenio, suscrito en la ciudad de Antofagasta, el 17 de octubre de 1971, fue promulgado por D.S. Nr. 195, de 12 de abril de 1972, del Ministerio de Relaciones Exteriores, y publicado en el Diario Oficial $\mathrm{N}^{\circ} 28.264$, del 31 de mayo de 1972. El texto puede consultarse en Convenios y Acuerdos en materias de Seguridad Social suscritos entre Chile y otros países, edición de la Subsecretaría de Previsión Social del Ministerio del Trabajo (Santiago, 1999), pp. 35 a 40.

3 Cfr. Benadava, Santiago, Derecho Internacional Público (Santiago, ConoSur LexisNexis Chile, 7a. Edición, 2001).

4 El texto utilizado por Grocio fue el de las Institutas de Gayo, cuyo estudio fue difundido, especialmente en el siglo XVI, entre los juristas del mos gallicus, conocido también como "humanismo jurídico", dentro de la doctrina del Derecho Común. Los juristas del mos gallicus cultivaban la llamada jurisprudencia elegante, dejando de lado la preferencia exclusiva por las Instituciones de Justiniano, que había predominado en el Ius Commune hasta el siglo XV. Vid. Francisco Tomás y Valiente, Manual de Historia del Derecho Español (Barcelona, Tecnos S.A., 1986). El texto de Gayo señala: Quod uero naturalis ratio inter omnes homines constituit, id apud omnes populos peraeque custoditur uocaturque ius gentium, quasi quo iure omnes gentes utuntur. Vide: Instituciones Jurídicas de Gayo, texto y traducción de Francisco Samper Polo (Santiago, Editorial Jurídica de Chile, 2000), p. XVIII. Según la traducción de Samper: ...en cambio, el que establece entre todos los hombres la razón natural es observado por todos los pueblos en igual medida y se llama derecho de gentes; como si dijéramos, derecho del que usan todas las gentes (Ibidem, p. 1). idea de un orden supranacional, en su célebre obra De Iure belli ac pacis $(1625)^{5}$.

Desde luego, muchos cambios han sucedido desde aquellas primeras formulaciones de quien es considerado, no sin alguna polémica en cuanto a su paternidad, el fundador del moderno Derecho Internacional ${ }^{6}$. Con todo, cabe destacar que una de las motivaciones más evidentes de la obra de Grocio era su estremecimiento ante la crudeza de su propio tiempo de violencia. No pudo imaginar el sabio holandés que el horror de los conflictos políticos y religiosos de su época podría ser superado, con largueza, en nuestro propio tiempo.

Pero cabe preguntar por qué esta cita a Grocio, en el marco de este artículo. Desde luego, ella se justifica tanto porque la noción de un orden jurídico positivo de carácter internacional arranca de ese autor, como también porque la misma concepción de ese orden internacional, en la obra de Grocio, tiene enorme importancia para una visión innovadora acerca de las relaciones internacionales en el mundo contemporáneo, y, para nuestros efectos, a los fines de enfocar críticamente el rol del Estado y la Sociedad en materias de Seguridad Social.

En efecto, en los siglos XVI y XVII, en los albores del Derecho Internacional, se consideraba que todo Derecho procedía del Derecho natural, con arreglo a las concepciones predominantes en la época, provenientes del lusnaturalismo católico y del Derecho Común Bajomedieval7. Por ello, en los comienzos de la Época Moderna, no se establecía una división tajante entre derecho internacional y derecho interno, facilitando la atribución de personalidad jurídica a los individuos bajo el derecho internacional ${ }^{8}$.

Así, Grocio pudo concebir el Derecho Internacional como aquél que la naturaleza ha hecho común entre las naciones, siguiendo la antigua definición romana sobre el Ius Gentium, pero a la vez considerando como sujetos de las relaciones

5 Para el texto de Grocio, vide: García Gallo, Alfonso, Manual de Historia del Derecho Español (Madrid, 1981), Tomo II, Fuentes, pp. 541 y ss.

6 Cfr. Benadava, op. cit., pp. 12-15.

7 Vid. Welzel, Hans, Derecho natural y justicia material. Introducción a la Filosofía del Derecho (Madrid, Aguilar, 1971).

8 Vid. Durán Bächler, Samuel, "El Individuo como Sujeto del Derecho Internacional. Nuevas Tendencias", en: Santiago Benadava et al., Nuevos Enfoques del Derecho Internacional (Santiago, Editoral Jurídica de Chile, 1992), p. 62. 
internacionales a la diversidad de principados, señoríos, repúblicas o monarquías, provenientes de la poliarquía medieval, al igual que había sido entendido por los griegos en relación a las ciudades-estados (polis), o por los romanos en cuanto a las diversas ciudadanías dentro de su Imperio9.

Con todo, el aporte más significativo de Grocio estaba referido a la concepción del fundamento de obligatoriedad del nuevo Ius Gentium o Derecho Internacional, sustentado por él en el principio del Pacta sunt servanda, es decir en el carácter de positividad de tal Derecho. Sin embargo, tal positividad no estaba limitada sólo a los acuerdos, tratados o convenciones, entre las naciones, sino al conjunto de normas, principios e instituciones jurídicas observadas por la comunidad internacional, definida del modo amplio antes señalado ${ }^{10}$.

Las ideas de Grocio, como sabemos, alcanzaron amplia difusión ${ }^{11}$. Así, en el siglo XVIII, William Blackstone (1723-1780), unos de los juristas ingleses más notables de su tiempo, reflejaba la opinión predominante de la época cuando escribía:

El derecho de las naciones es un sistema de reglas deducible por la razón natural y establecido por consenso universal entre los habitantes civilizados del mundo con el fin de resolver todas las disputas, regular todas las ceremonias y cortesías, y asegurar la observancia de la justicia y la buena fe, en esas relaciones que deben ocurrir frecuentemente entre dos o más Estados independientes y los individuos pertenecientes a cada uno de ellos ${ }^{12}$.

Por ello, ese Derecho de las naciones estaba constituido tanto por las prácticas consuetudinarias reconocidas entre las naciones civilizadas, como también por los tratados y convenciones libremente acordados por los sujetos de ese Derecho.

A fines del mismo siglo XVIII, y sólo a partir de la obra de Jeremy Bentham (1748-1832), gran expositor de las ideas jurídicas fundamentales de su época, críticas del iusnaturalismo de las obras anteriores, se acunó la expresión "Derecho Internacional", restringiendo su alcance al derecho que se refiere a las transacciones mutuas entre soberanos

9 Vid. Koschaker, Paul, Europa y el Derecho Romano (Madrid, Revista de Derecho Privado, 1955).

10 Cfr. Welzel, op. cit. (nota 7).

11 Vid. Truyol y Serra, Antonio, Historia de la Filosofía del Derecho y del Estado (Madrid, Alianza, 1988).

12 Citado por Durán Bächler, op. cit. (nota 8), p. 63. como tales, y que él mismo consideró equivalente a la rama del derecho que se conoce comúnmente bajo el nombre de derecho de las naciones ${ }^{13}$. Fue Bentham quien separó tajantemente el Derecho Internacional, como Derecho de los Estados, del Derecho Interno, propio de uno solo ${ }^{14}$.

Por cierto, es conocida la influencia de Bentham en el pensamiento de Andrés Bello (1781-1865), quien es autor además de una de las primeras obras de Derecho Internacional en el ámbito latinoamericano, titulada Principios de Derecho de Gentes, en la que son recogidas, en parte, las ideas de aqué ${ }^{15}$, y que tiene una larga influencia en nuestra doctrina y jurisprudencia.

Sin embargo, ya en el siglo XIX, dos juristas de amplia influencia, Joseph Story (1779-1845), norteamericano, y John Austin (1790-1859), inglés, anuncian las corrientes del iuspositivismo prevalecientes a partir de la segunda mitad de ese siglo ${ }^{16}$. Sus ideas fomentaron la noción que el individuo no es propiamente un sujeto de derecho internacional, al precisar el concepto de Derecho Internacional Público y Privado: el primero rige sólo a los Estados; el segundo, a los individuos en sus asuntos internacionales ${ }^{17}$.

Más tarde, en la primera mitad del siglo XX, las concepciones positivistas de Hans Kelsen (18811973), y su Teoría Pura del Derecho, fortalecieron la tajante división entre Derecho Internacional y Derecho Interno, mas no afectaron a la noción de las fuentes del Derecho Internacional, radicadas en las prácticas consuetudinarias y en los tratados y convenciones. Por ello, Kelsen profundiza la división entre Derecho Internacional Público y Privado ${ }^{18}$.

Sin embargo, cabe plantear si ese enfoque es adecuado a una reflexión sobre el rol del Estado y la sociedad en relación a la Seguridad Social en nuestra época, que debiera considerar, entre otros aspectos, el evidente proceso de desarrollo de los vínculos entre las personas e instituciones más allá

13 Ibidem, p. 64.

14 Cfr. Truyol y Serra, Antonio, Historia del Derecho Internacional Público (Madrid, Tecnos, 1998).

15 Vid. Hanisch Espíndola, Hugo, Andrés Bello y su obra en Derecho Romano (Santiago, Ediciones del Consejo de Rectores de las Universidades Chilenas, 1983).

16 Cfr. Welzel, op. cit., (nota 7).

17 Durán Bächler, op. cit. (nota 8), p. 64.

18 Kelsen, Hans, Principios de Derecho Internacional Público (Buenos Aires, El Ateneo, 1965). 
de los viejos límites de los Estados tradicionales de base nacional homogénea y de su derecho. Por ello, el tema de este artículo está referido, en primer término, al ámbito de las relaciones internacionales concebidas en un sentido amplio, y no sólo entre los Estados. Sin duda, tal perspectiva de las relaciones internacionales resulta importante, atendida la complejidad y diversidad del mundo contemporáneo.

En segundo lugar, he pretendido precisar ese marco de referencia en relación al desarrollo del moderno Derecho Internacional de los Derechos Humanos, para comprender de manera más adecuada algunos problemas que plantean tales relaciones internacionales en un ámbito geográfico delimitado, cual es la denominada Región Magallánica -que abarca el sur austral de Chile y Argentina-, en razón de la efectiva y cotidiana realidad de tales relaciones en esa región, unida por una misma y extensa Patagonia ${ }^{19}$.

Por cierto, la actual vigencia del Convenio de Seguridad Social, suscrito entre Chile y Argentina en 1971, y con pleno vigor a partir de 1972, facilita la tarea de constatar las carencias y perspectivas que el mismo presenta en relación a las nuevas relaciones internacionales en la dimensión de ese Derecho Internacional de los Derechos Humanos. Desde luego, según veremos más adelante, el propio Convenio fue concebido para regular la situación de los trabajadores migrantes de esa austral región. Por lo demás, la noción de las relaciones internacionales, entendidas del modo antes indicado, es un punto de vista que justifica volver sobre este tema, ya abordado en obras especializadas ${ }^{20}$.

\section{LA NOCIÓN DE ESTADO: EL ESTADO NEOLIBERAL}

En cuanto a la noción prevaleciente del Estado, ella determina el rol que al mismo le cabe en

19 Vid. Martinic Beros, Mateo, Historia de la Región Magallánica (Punta Arenas, Ediciones de la Universidad de Magallanes, 4 vols., 2006).

20 Vid. Novoa Fuenzalida, Patricio, Derecho de Seguridad Social (Santiago, Editorial Jurídica de Chile, 1977), pp. 479 y ss.; Gajewski Molina, Reinardo Juan, La continuidad de afiliación internacional en la Seguridad Social: situación actual; problemas de aplicación, y, alternativas de perfeccionamiento y/o solución (Santiago, tesis para optar al grado de Magíster en Derecho con mención en Seguridad Social de la Universidad de Chile, s.e., 1991, 4 vols). materias de Seguridad Social, puesto que incide en la concepción aceptada sobre la naturaleza, carácter y funciones de ese Estado, en general, y en materias de Seguridad Social, en particular.

Respecto de tal noción del Estado, más allá de una especulación teórica, conviene a los efectos de esta exposición, destacar los rasgos de la actual concepción predominante de Estado, nacida en el curso de los últimos 50 años del siglo XX, para que, en su revisión crítica, sea posible detectar sus falencias y probabilidades de cambio.

Tal como fue destacado al inicio de esta ponencia, el Estado actual es una construcción histórica que, en lo inmediato, surge del mundo bipolar posterior a la segunda Gran Guerra, marcado por la denominada Guerra Fría ${ }^{21}$.

En efecto, el período de entreguerras, en la primera mitad del siglo XX, contempló el desarrollo del llamado Estado Benefactor, que subsistió en gran medida hasta los años setenta de ese siglo ${ }^{22}$.

Sin embargo, en los últimos 30 años, en los Estados del llamado ámbito occidental, comenzó a predominar la nueva ideología del Neoliberalismo, que afectó la noción misma del Estado y su Derecho $^{23}$.

Con la caída de los llamados socialismos reales $^{24}$, a partir de fines de los años 80 , esa nueva ideología apareció como triunfadora con una fuerza incontrastable.

Al respecto, cabe citar las palabras del Director General de la O.I.T., Michel Hansenne, en su Memoria presentada a la Conferencia Internacional del Trabajo de 1994:

En todas partes, o casi, se reafirma la confianza en la empresa privada. Los jefes de empresa son tratados en los grandes medios de comunicación con la misma consideración que los políticos, los atletas y los artistas. En el mundo entero, el Estado se va retirando del sector económico y se extiende la privatización. Al mismo tiempo, por la presión que ejercen las diversas formas de liberalización, el Estado pierde cada vez más el dominio sobre el funcionamiento del

\footnotetext{
21 Vid. Hobsbawm, Eric, Historia del Siglo XX (Buenos Aires, Crítica, 1998).

22 Ibídem, pág. 260 y ss

23 Ibídem, pág. 551 y ss

24 Ibídem, pp. 372 y ss.
} 
mercado. En todas partes está impugnándose el Estado Benefactor...Así pues, en tan sólo unos cuantos años, y por primera vez en la historia de la O.I.T., la economía de mercado se ha convertido en la norma universalmente aceptada. Tal es el contexto en que nuestra Organización deberá actuar en favor de la justicia social. Y dentro de esa nueva norma universal, el frágil equilibrio entre el Estado y el mercado se ha inclinado claramente en provecho de éste último ${ }^{25}$.

En el caso chileno, el historiador Mario Góngora, en su conocida obra Ensayo histórico sobre la noción de Estado en Chile en los siglos XIX y $X X$, advertía claramente acerca de la disolución de la noción de Estado predominante desde mediados del siglo XX, el llamado Estado de compromiso, y su reemplazo por el Estado neoliberal ${ }^{26}$.

Los rasgos fundamentales del Estado Neoliberal, según Anthony Giddens, reconocido pensador británico, son los siguientes: gobierno mínimo; sociedad civil autónoma; fundamentalismo del mercado; autoritarismo moral más fuerte; individualismo económico; flexibilidad del mercado laboral, como la de cualquier otro mercado; aceptación de la inequidad social; nacionalismo tradicional; Estado de bienestar sólo como salvaguardia de seguridad; modernización lineal; baja conciencia ecológica; realismo teórico respecto del orden internacional, y pertenencia al mundo bipolar $^{27}$.

Esta descripción del Estado Neoliberal, si bien general, es muy certera en su caracterización. Aunque algunos de los aspectos que menciona correspondan a situaciones inexistentes, como es el caso del mundo bipolar, derribado junto con el Muro de Berlín, en 1989, empero sus efectos persisten. Del mismo modo, el surgimiento en el discurso político contemporáneo de las ideas de protección y responsabilidad social, parecieran limitar los alcances de ese Estado neoliberal. Sin embargo,

25 Citado por Montt Balmaceda, Manuel, Principios de Derecho Internacional del Trabajo. La O.I.T (Santiago, Editorial Jurídica de Chile), p. 63.

26 Góngora, Mario, Ensayo sobre la noción de Estado en Chile en los siglos XIX y XX (Santiago, Ediciones La Ciudad, 1981).

27 Giddens, Anthony, The Third way. The renewal of social democracy (Cambridge, Polity Press, 1998) cap. 1, citado por Gonzalo Arroyo, S.J., "Reflexión sobre el Neoliberalismo", en: Mensaje, Nov. 1999, p. 19. el neoliberalismo continúa operando como una ideología influyente y su construcción institucional sigue vigente en muchos aspectos ${ }^{28}$.

Pues bien, cabe plantear si el Estado neoliberal, construido a partir de los supuestos de la Guerra Fría, es capaz de enfrentar seriamente los desafíos de la moderna globalización de la economía y la sociedad, en particular en relación a las materias propias de la Seguridad Social.

\section{EL MODERNO DERECHO INTERNACIONAL DE LOS DERECHOS HUMANOS Y LA SEGURIDAD SOCIAL}

La paradoja del desarrollo del Estado neoliberal es que, en la misma medida que logró su afianzamiento, desarrolló un conjunto de normas, principios $e$ instituciones de rango internacional, que lo vinculan a la concepción de los derechos humanos, y, a la vez, la globalización de la economía y la sociedad le sujetan a ese orden internacional de carácter plural y no sólo estatal.

Desde luego, ese Derecho Internacional de los Derechos Humanos está referido de modo importante a las materias propias de la Seguridad Social. Sin embargo, aún se expresa a través de tratados y convenciones, ya que la práctica de los mismos dista mucho de llegar a constituir un derecho consuetudinario de las naciones civilizadas.

Por otra parte, el Derecho Internacional de Derechos Humanos tiene un alcance diverso en relación a las distintas instancias en que ha sido establecido, ya sea al nivel de las Naciones Unidas, o bien en el ámbito de organizaciones internacionales de carácter regional.

Para los efectos de esta exposición, aludiremos sólo al ámbito de las Naciones Unidas, y a ciertos pactos multilaterales o bilaterales, de especial relevancia para el caso chileno.

28 Tal como señala el profesor Carlos Peña: ...no lo olvidemos, la (chilena) es una de las veinte sociedades más desiguales del mundo. Esa desigualdad tiene muchas causas. Débiles sistemas de protección social; ciudades geográficamente estratificadas; políticas sociales contributivas y no de cobertura universal; un sistema de clases que nadie cuestiona; empresarios que confunden la racionalidad económica con la avaricia; una élite intelectual endogámica y complaciente. Vid. El Mercurio, cuerpo de Reportajes, $1^{\circ}$ de octubre de 2006 . 
A) Las Naciones Unidas y la Organización Internacional del Trabajo.

En el ámbito de las Naciones Unidas, ya la Declaración Universal de los Derechos Humanos, aprobada por la Asamblea General en 1948, en sus artículos 22, 25 y 28, establecía los principios fundamentales en materia de Seguridad Social. En efecto, el artículo 22 declara que toda persona, como miembro de la sociedad, tiene derecho a la seguridad social y a obtener mediante el esfuerzo nacional y la cooperación internacional, habida cuenta de la organización y los recursos de cada Estado, la satisfacción de los derechos económicos, sociales y culturales, indispensables a su dignidad y al libre desarrollo de su personalidad ${ }^{29}$.

De esta manera, el derecho a la seguridad social es considerado como uno de los derechos económicos, sociales y culturales fundamentales, en concordancia con la Declaración de Filadelfia, aprobada por la Organización Internacional del Trabajo en 1944 (Sección III, letra f) ${ }^{30}$.

Por ello, el Pacto Internacional de Derechos Económicos, Sociales y Culturales, adoptado por la Asamblea General en 1966, y en vigor desde 1976, establece en su artículo 9, Los Estados Partes en el presente Pacto reconocen el derecho de toda persona a la seguridad social, incluso al seguro social ${ }^{31}$.

Del mismo modo, la Declaración y Programa de Acción de Viena, aprobada en la Conferencia Mundial de Derechos Humanos, de 1993, establece las competencias del Alto Comisionado de las Naciones Unidas para los Derechos Humanos. El Alto Comisionado es el principal funcionario de las Naciones Unidas responsable de los derechos humanos y rinde cuentas al Secretario General. Su propósito es dirigir el movimiento internacional de derechos humanos, desempeñando la función de autoridad moral y portavoz de las víctimas ${ }^{32}$.

29 Vid. el texto de la Declaración en Evans, Enrique, Los derechos constitucionales (Santiago, Editorial Jurídica de Chile, $2^{\text {a }}$ edición, 1999), pág. 35.

30 Vid. El texto en: http://www.ilo.org/public/spanish/about/ iloconst.htm\#anexo

31 El Pacto fue suscrito por Chile el 16 de septiembre de 1969 , y promulgado por D.S. N ${ }^{\circ} 326$, de 28 de abril de 1989 , del Ministerio de Relaciones Exteriores, se publicó en el Diario Oficial de 27 de mayo de 1989. El texto en Evans, op. cit., pág. 54-62.

32 Vide la página oficial en internet: $h t t p: / / w w w . o h c h r . o r g /$ spanish/about/hc/index.htm
Por cierto, la mayor innovación en la materia está en el reciente establecimiento del Consejo de Derechos Humanos, por la Resolución N 60/251, de 15 de marzo de 2006, de la Asamblea General de las Naciones Unidas, en sustitución de la anterior Comisión de Derechos Humanos, con amplias y esperanzadoras atribuciones en materia de promoción y supervigilancia de la observancia y efectivo cumplimiento por parte de los Estados de sus obligaciones respecto de todos los derechos humanos ${ }^{33}$. Actualmente, este Consejo está constituído y ha celebrado Sesiones, en su sede de Ginebra, desde el mismo año $2006^{34}$.

Por otro lado, la acción de las Naciones Unidas ha sido complementada por la Organización Internacional del Trabajo (O.I.T.), instituida bajo el alero de la Sociedad de las Naciones, en el Tratado de Versalles, de 1919, y actualmente uno de los órganos especializados más importantes de la O.N.U.

La O.I.T., ha desarrollado una amplia labor en materia de Seguridad Social, que se manifiesta en la aprobación de diversos Convenios. Antes de la Segunda Guerra Mundial, dichos Convenios procuraban propiciar la protección de determinadas categorías de trabajadores contra contingencias concretas. Muchos de estos primeros convenios hoy se consideran obsoletos. En la posguerra, se hicieron esfuerzos por establecer normas que instituyeran regímenes de seguridad social y abarcaran todas o varias ramas de seguridad social. Al respecto, la norma fundamental es el Convenio $\mathrm{N}^{\circ} 102$.

El Convenio sobre la Seguridad Social (norma mínima), adoptado en 1952 ( $\left.\mathrm{N}^{\circ} 102\right)$, abarca las nueve ramas principales de la seguridad social, a saber: asistencia médica; prestaciones monetarias de enfermedad; prestaciones de desempleo; presta-

33 El texto de la Resolución en: $h$ ttp://www.ohchr.org/spanish/ bodies/hrcouncil/docs/A.RES.60.251._Sp.pdf

34 En materia de Convenios de la ONU suscritos por Chile, cabe mencionar la Convención Internacional sobre protección de los derechos de los trabajadores migratorios y sus familiares, ratificado por D.S. № 84, de 12 de abril de 2005, y publicado el Diario Oficial de 8 de junio de 2005, cuyo artículo 27, numeral 2, reconoce el derecho al reembolso de contribuciones aportadas "cuando la legislación aplicable no permita que los trabajadores migratorios o sus familiares gocen de alguna prestación”. Esta Convención, en general, favorece a los trabajadores migratorios en Chile, pero no reconoce los derechos de éstos en relación a los períodos en que se encontraren fuera del territorio nacional y luego retornaren a él. 
ciones de vejez; prestaciones en caso de accidente de trabajo y enfermedad profesional; prestaciones familiares; prestaciones de maternidad; prestaciones de invalidez, y prestaciones de sobrevivientes. Un Estado debe aceptar las obligaciones relativas a tres de estas ramas para poder ratificar dicho convenio cuya norma mínima se define respecto del alcance de la protección y las prestaciones, incluido el monto de las mismas. El convenio sustenta la idea del nivel general de seguridad social que, paulatinamente, debe alcanzarse en todas partes, dado que el régimen puede adaptarse a las condiciones socioeconómicas imperantes en cualquier país, independientemente del grado de desarrollo del mismo.

Asimismo, se establecieron nuevos instrumentos con miras a complementar o revisar los convenios adoptados antes de la segunda Guerra Mundial y proporcionar un mayor grado de protección que el estipulado en el Convenio $\mathrm{N}^{\circ} 102$. También se hicieron esfuerzos para proceder rama por rama. Así, surgen los siguientes Convenios:

- Convenio sobre las prestaciones en caso de accidentes del trabajo y enfermedades profesionales, de 1964, $\left(\mathrm{N}^{\circ} 121\right)$;

- Convenio sobre las prestaciones de invalidez, vejez y sobrevivientes, de 1967 ( $\left.\mathrm{N}^{\circ} 128\right)$;

- Convenio sobre la asistencia médica y prestaciones monetarias de enfermedad, de 1969 $\left(\mathrm{N}^{\circ} 130\right)$;

- El Convenio sobre el fomento del empleo y la protección contra el desempleo, 1988 ( $\left.\mathrm{N}^{\circ} 168\right)$, detalla los elementos indispensable del régimen de prestaciones de desempleo que, junto con otros medios tales como los servicios de empleo, la orientación y la formación profesionales, han de propiciar una activa política de empleo como objetivo nacional prioritario $^{35}$.

Paralelamente, la OIT ha elaborado normas que se aplican a todas las ramas de la seguridad social y

35 El convenio no sólo protege contra el desempleo total sino también contra la pérdida de ingresos, a raíz de desempleo temporario o suspensión de trabajo temporal, y exhorta a los Estados Miembros de la OIT a promover oportunidades de empleo suplementarias para determinas categorías de personas desafortunadas y a ampliar progresivamente la protección a los nuevos solicitantes de empleo. Además de las disposiciones habituales, prohíbe la discriminación fundada en la edad o la discapacidad. son particularmente pertinentes para los trabajadores migrantes. En esta materia, destaca el Convenio sobre la igualdad de trato (seguridad social), de $1962\left(\mathrm{~N}^{\circ}\right.$ 118), que estipula que todo Estado ratificante ha de reservar igualdad de trato a los trabajadores de otro Estado ratificante en lo que respecta a las nueve ramas de la seguridad social, aunque las obligaciones del convenio hayan sido aceptadas con respecto a una sola de esas ramas. El pago de prestaciones a largo plazo a personas residentes en el extranjero debe asegurarse tanto a los nacionales del propio país como a los nacionales de cualquier otro Estado que haya aceptado las obligaciones del Convenio relativas a la rama correspondiente. Además, en relación con los niños residentes en el territorio de cualquier Estado ratificante, se debe garantizar el beneficio de las asignaciones familiares a los propios nacionales y a los nacionales de otros Estados que hayan aceptado las obligaciones que emanan de dicha rama. Este Convenio dejó de lado el anterior Convenio $\mathrm{N}^{\circ}$ 048, de 1935 , sobre la conservación de los derechos de pensión de los migrantes. Cabe destacar que ninguno de ellos había sido ratificado por Chile ni Argentina, al año 1971.

Por otra parte, el Convenio sobre la conservación de los derechos en materia de seguridad social, de 1982 ( $\left.\mathrm{N}^{\circ} 157\right)$, prevé la creación de un régimen internacional para que quienes trabajan o están fuera de su país conserven los derechos relacionados con todas las ramas de la seguridad social. En los anexos de la Recomendación № 167, que complementa este convenio, se dan ejemplos de disposiciones destinadas a propiciar la creación de instrumentos bilaterales o multilaterales en materia de seguridad social ${ }^{36}$.

Por último, cabe destacar también la labor de la Asociación Internacional de Seguridad Social, fundada en 1927, y con sede actual en Ginebra, que es una importante Organización No Gubernamental (O.N.G.), con una amplia base de información ${ }^{37}$.

\section{B) La Unión Europea.}

En el curso del proceso de unificación europea, en los últimos 50 años del siglo XX, han sido aprobados varios textos relativos a la Seguridad

36 Los textos de los Convenios de la O.I.T., en el sitio: $h$ ttp:// www.ilo.org/public/spanish/standards/index.htm

37 Vid: http://www.issa.int/span/homef.htm 
Social, que presentan un grado muy elevado de integración y efectividad.

Entre tales textos, cabe destacar los siguientes:

1. El Convenio Europeo de Derechos del Hombre y de Libertades Fundamentales, aprobado en Roma en 1950, que si bien no contempló en forma expresa el derecho a la seguridad social, igualmente hizo aplicables los derechos enunciados en la Declaración Universal de las Naciones Unidas de 1948.

2. El Acuerdo Europeo sobre Seguridad Social, y su Protocolo Adicional, en vigor desde 1954, que contemplaba normas generales en materia de regímenes de seguridad social relativos a vejez, invalidez y sobrevivencia.

3. El Tratado Constitutivo de la Comunidad Europea, aprobado en Roma en 1957, que contemplaba una estrecha colaboración entre los Estados miembros en el ámbito social, particularmente en las materias relacionadas con... la seguridad social.

4. El Convenio sobre Instituciones Comunes a las Comunidades Europeas, aprobado igualmente en Roma en 1957, crea el Consejo Económico y Social, estableciendo en su artículo 51, que El Consejo, por unanimidad y a propuesta de la Comisión, adoptará, en materia de seguridad social, las medidas necesarias para el establecimiento de la libre circulación de los trabajadores, creando, en especial, un sistema que permita garantizar a los trabajadores migrantes y a sus derechohabientes:

a) La acumulación de todos los períodos tomados en consideración por las distintas legislaciones nacionales para adquirir y conservar el derecho a las prestaciones sociales, así como para el cálculo de éstas;

b) El pago de las prestaciones a las personas que residan en los territorios de los Estados miembros.

5. La Carta Social Europea, aprobada en Turín en 1961, establece que todos los trabajadores y sus derechohabientes tienen derecho a la seguridad social, desarrollado en forma detallada en el artículo 12 de la Carta. Fue revisada y ampliada en 1996, y con vigencia desde 1999.
6, El Código Europeo de Seguridad Social, aprobado en Estrasburgo, en 1964, y en vigencia desde 1968, cuyo objetivo es estimular el desarrollo de la seguridad social en todos los Estados miembros del Consejo de Europa. El Código fija una serie de normas que las Partes se comprometen a incluir en sus sistemas de seguridad social.

7. La Convención Europea de Seguridad Social, aprobada en París, en 1972, y en vigencia desde 1977, reconoce los cuatro principios fundamentales del derecho internacional de la seguridad social:

a. La igualdad de tratamiento;

b. Unicidad de la Legislación aplicable;

c. Conservación de los derechos adquiridos o en proceso de adquisición; $y$

d. Servicio de prestaciones en el extranjero.

Para la aplicación de las normas anteriores, cabe destacar las disposiciones contenidas en la Decisión del Parlamento Europeo, de 9 de marzo de 1994, sobre el Estatuto del Defensor del Pueblo, y la Recomendación del Consejo de Ministros, de 24 de junio de 1992, sobre los criterios comunes relativos a recursos y prestaciones suficientes en los sistemas de protección social.

Por último, cabe mencionar que, a raíz del $50^{\circ}$ aniversario de la Declaración Universal de los Derechos Humanos, en diciembre de 1998, el Consejo Europeo de Colonia, del 3 y 4 de junio de 1999, decidió redactar una nueva Carta de los derechos fundamentales. Así, la Carta de Derechos Fundamentales de la Unión Europea, finalmente aprobada en la Cumbre Europea de Niza de 2000, constituye el acervo europeo común en materia de Derechos Fundamentales, y recoge en un único texto el conjunto de los derechos civiles, políticos, económicos y sociales de los ciudadanos europeos y de todas las personas que viven en el territorio de la Unión.

La Carta no otorga derechos nuevos a los ciudadanos europeos, ya que todos los derechos consignados en ella proceden de Convenciones, Tratados o de la jurisprudencia comunitaria, aunque algunos son nuevos en el sentido de que responden a inquietudes resultado de la evolución de la ciencia y la sociedad, como pueden ser las nuevas tecnologías o la biotecnología (bioética, protección de datos). 
Así pues, la razón de elaborar un nuevo texto sobre derechos fundamentales se apoya no en la necesidad de añadir nuevos derechos, sino en hacer más visibles los ya reconocidos y recopilar los derivados de las sentencias de la Corte Europea de Derechos Humanos. Por otro lado, se trataba igualmente de incorporar, junto a los derechos civiles y políticos tradicionales, los derechos sociales y económicos, en un texto único, lo cual no se había dado todavía en ningún acuerdo internacional o europeo.

La Carta supone, además, un paso adelante en la nueva fase de integración, que tiene una vocación decididamente política, y que se manifiesta en el actual proceso de aprobación del Tratado de Roma, de 29 de octubre de 2004, por el que se establece una Constitución de la Unión Europea. Esta supone un instrumento fundamental de legitimidad política y moral, que pretende expresar la vocación democrática de las sociedades europeas ${ }^{38}$.

C) La Organización de Estados Americanos (OEA).

En el ámbito regional americano, la labor de la O.E.A. en materia de seguridad social se ha manifestado en la aprobación de la propia Carta Constitutiva, adoptada en Colombia en 1948, y en vigor desde 1951, y en la Convención Americana sobre Derechos Humanos, o Pacto de San José de Costa Rica, de 1969.

La Carta de la OEA, declara como uno de sus principios que la justicia y la seguridad sociales son base de una paz duradera, tal como lo había hecho el Tratado de Versalles de 1919.

La Carta establece, como derechos y deberes fundamentales de los Estados, en su art. 45, letra h), que los Estados convienen en aplicar los siguientes principios, entre los cuales enumera el desarrollo de una política eficiente de seguridad social, que se cumple a través de la Comisión y la Corte Interamericana de Derechos Humanos.

A su vez, el Pacto de San José de Costa Rica, establece en su artículo 26, como principio de Desarrollo Progresivo que Los Estados Partes se comprometen a adoptar providencias, tanto a nivel interno como mediante la cooperación internacional, especialmente económica y técnica, para

38 Vid. los instrumentos citados de la Unión Europea, en: http://eur-lex.europa.eu/es/index.htm lograr progresivamente la plena efectividad de los derechos que se derivan de las normas económicas, sociales y sobre educación, ciencia y cultura, contenidas en la Carta de la Organización de los Estados Americanos, reformada por el Protocolo de Buenos Aires, en la medida de los recursos disponibles, por vía legislativa u otros medios apropiados $^{39}$. En particular, el Protocolo de San Salvador, de 19 de noviembre de 1988, contempla los llamados derechos económicos y sociales, incluso la seguridad social (art. 9) ${ }^{40}$.

D) La Organización Iberoamericana de Seguridad Social (OISS).

Igualmente, en el ámbito regional iberoamericano, destaca la Organización Iberoamericana de Seguridad Social (OISS), que es un organismo internacional, de carácter técnico y especializado, cuya finalidad es promover el bienestar económico y social de los países iberoamericanos y de todos aquellos que se vinculan por el idioma español y portugués mediante la coordinación, intercambio y aprovechamiento de sus experiencias mutuas en Seguridad Social.

La OISS encuentra sus primeros antecedentes en el Primer Congreso Iberoamericano de Seguridad Social, celebrado en Barcelona en 1950, en cuyo seno se creó una Secretaría de apoyo a ulteriores congresos que recibiría el nombre de Comisión Iberoamericana de Seguridad Social. En el Segundo Congreso Iberoamericano de Seguridad Social, celebrado en Lima (Perú) en 1954, con la presencia de la mayoría de los países integrantes de la Región, junto con representantes de la Organización Internacional del Trabajo (OIT), de la Organización de Estados Americanos (OEA) y la Asociación Iberoamericana de Seguridad Social (AISS), quedó aprobada la Carta Constitucional de la OISS ${ }^{41}$.

Entre las actividades que actualmente desarrolla esta Organización, de acuerdo con las Cumbres Iberoamericanas de Jefes de Estado y de Gobierno,

39 El Pacto fue suscrito por Chile el 22 de noviembre de 1969, en San José de Costa Rica, y promulgado por D.S. N ${ }^{\circ} 873$, de 23 de agosto de 1990, del Ministerio de Relaciones Exteriores, se publicó en el Diario Oficial de 5 de enero de 1991.

40 Vid. El texto del Protocolo en: http://www.cidh.oas.org/ Basicos/Basicos4.htm

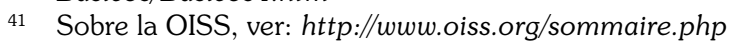


destacan dos proyectos que representarán una aportación significativa a la evolución y desarrollo de los Sistemas de Seguridad Social Iberoamericanos: Social.

- El Código Iberoamericano de Seguridad

- El Banco de Información de los Sistemas de Seguridad Social Iberoamericanos.

En la línea de la OISS, destaca el Plan de Acción aprobado en la Segunda Cumbre de las Américas, celebrada en Santiago de Chile, en 1998, que acordó fomentar la negociación de acuerdos bilaterales o multilaterales, relacionados con el retorno de los beneficios de seguridad social devengados por trabajadores migrantes.

E) La cláusula social en los pactos de integración.

Una nueva manifestación de la protección internacional de los derechos de las personas en el ámbito de la Seguridad Social, lo constituye la llamada cláusula social, surgida en el marco de las políticas de negociación de acuerdos de integración comercial, aduanera y económica, desarrolladas por Chile a partir de 1990, como ocurre, entre otros, con la Unión Europea, el MERCOSUR, el Tratado de Libre Comercio con los Estados Unidos de Norteamérica y el Tratado de Libre Comercio con Canadá ${ }^{2}$.

En este ámbito, la cláusula social es definida como: aquella cláusula, incorporada en un tratado, convenio o acuerdo internacional de comercio por el cual las partes signatarias someten su actuar dentro de los márgenes acordados en ella, comprometiéndose a respetar o, eventualmente, hacer respetar ciertos derechos sociales contemplados, bajo pena de perder las ventajas recíprocamente otorgadas o las que hayan acordado a terceros países, o aún la simple rescisión por incumplimiento de todo el acuerdo ${ }^{43}$.

La eficacia de dicha cláusula está aún por verificarse en su aplicación práctica, pero representa un importante avance en cuanto a la protección internacional de los derechos sociales, y entre ellos de

42 Cfr. Cuevas García, Julio César y Pérez Hernández, Álvaro Enrique, La cláusula social en el ámbito internacional. Su incorporación en los Acuerdos de integración suscritos por Chile (Santiago, Memoria de Prueba, Facultad de Derecho Universidad de Chile, s.e., 2005).

43 Ibídem, pág, 84.

los de seguridad social. Sin duda que esta cláusula social es la más clara manifestación de la paradoja que apuntamos al comienzo, en cuanto a la vinculación del estado neo-liberal a los principios de la protección internacional de los derechos humanos, y de allí su ambigüedad.

F) Los problemas de la internacionalización de la Seguridad Social.

Según lo expuesto, existen numerosos textos de vigencia supranacional que demuestran la existencia de lo que los autores denominan la internacionalización de la Seguridad Social ${ }^{44}$. Obviamente, esa internacionalización no significa que todos los Estados deban organizar sus Sistemas de Seguridad Social en forma igual, pero tampoco puede significar, como sostiene una eminente doctrina chilena ${ }^{45}$, que cada Estado pueda decidir por sí la intensidad con que incorpora en su práctica política y jurídica el Derecho Internacional de los derechos humanos en materias de Seguridad Social.

Por ende, cabe plantear el problema de las relaciones del Derecho Internacional de Seguridad Social con el derecho interno de cada Estado, y sus efectos con respecto a las personas de cualquier Estado, quienes son, en última instancia, los afectados o perjudicados por tales relaciones.

Desde luego, cabe destacar que el Derecho Internacional de Seguridad Social, fundado en los derechos humanos, no puede ser considerado bajo la sola perspectiva del Derecho Internacional Privado, como argumenta en Chile el profesor Patricio Novoa ${ }^{46}$, ya que los derechos humanos no son simples facultades que puedan exigirse de otros individuos o de Estados en una actuación propia del Derecho Privado.

En efecto, el Derecho Internacional de los Derechos Humanos tiene la importancia de colocar en un rol de la mayor trascendencia a los individuos frente al Estado, como detentadores de unas facultades o atributos subjetivos, reconocidos por el propio orden internacional ${ }^{47}$.

44

45

46

47$$
\text { 47 }
$$

\footnotetext{
Vid. Novoa, op. cit., pp. 11 y 479.

Ibídem, pp. 491 y ss.

Ibídem, pp. 493 y ss.

Cfr. Gajewski, op. cit, Vol. II, pág. 182-183. En el mismo sentido, la obra del destacado jurista brasileño Antônio Augusto Cançado Trindade, El derecho internacional de los derechos humanos en el siglo XXI, (Santiago, Ed. Jurídica de Chile, 2a Edición, 2006).
} 
Por ello, las actuales relaciones internacionales no consisten sólo en relaciones entre Estados, sino, tal como señalaban Grocio o Blackstone, en su concepción del ius gentium o derecho de gentes, ellas se manifiestan en un conjunto de relaciones aplicable a todos los sujetos de Derecho Internacional, ya sea Estados u organizaciones, y creado por esos mismos sujetos, en una práctica propia de sociedades civilizadas que deben una especial protección a los derechos de la persona humana ${ }^{48}$.

Ahora bien, en el caso de Chile, la modificación del artículo $5^{\circ}$, inciso $2^{\circ}$, de la Constitución vigente, por medio de la reforma constitucional de 1989, tiene una gran importancia en el tema que nos interesa. En efecto, de acuerdo a dicha reforma constitucional, el ejercicio de la soberanía reconoce como limitación el respeto a los derechos esenciales que emanan de la naturaleza humana, y agrega que es deber de los órganos del Estado respetar y promover tales derechos, garantizados por esta Constitución, así como por los tratados internacionales ratificados por Chile y que se encuentren vigentes.

Ya ha sido observado que el problema que presenta la nueva norma radica, fundamentalmente, en determinar el rango de los tratados internacionales que versan sobre derechos esenciales que emanan de la naturaleza humana, o simplemente de derechos humanos ${ }^{49}$.

Como se sabe, el problema ha sido resuelto por variadas opiniones doctrinarias y jurisprudenciales ${ }^{50}$. Sin embargo, a nuestro juicio, el problema no puede ser resuelto de una manera amplia, sino tomando en consideración lo que la doctrina internacional denomina como el carácter de autoejecutable o no de un tratado. Este carácter consiste en la cualidad de una disposición de Derecho Internacional de ser aplicada directamente, no obstante la necesidad de su promulgación y publicación, sin ningún otro complemento interno ${ }^{51}$.

48 Cfr. Rawls, John, El derecho de gentes y una revisión de la idea de razón pública (Barcelona, Paidós, 2001).

49 Vid. Grossman, Claudio, "Algunas consideraciones sobre el valor del Derecho Internacional de Derechos Humanos en el Derecho Interno", en: Benadava et. al, op. cit. (nota 8), pp. 77 y ss.

50 Llanos Mansilla, Hugo, Los Tratados internacionales en la Constitución de 1925 y en la jurisprudencia, en: Ius et Praxis, Talca, 2003, vol.9, no.1, p.223-244.

51 Vid. Benadava, Santiago, "Las relaciones entre Derecho Internacional y Derecho Interno ante los Tribunales Chilenos", en: Benadava et. al., op. cit. (nota 8), pp. 9 y ss.
Por cierto, no todas las disposiciones de los Tratados y Convenciones antes referidos tienen el carácter de autoejecutables, pero no por ello dejan de estar reconocidos como parte del Derecho interno, por mandato del art. 5을 de la Constitución, y sin perjuicio de la responsabilidad internacional del Estado que pretenda desconocer su cumplimiento ${ }^{52}$. De esta suerte, estimamos que en caso de conflicto entre una norma internacional de derechos humanos, debidamente promulgada y publicada, y una norma legal interna, los jueces deberán atender al carácter de autoejecutable o no de la primera para determinar su primacía sobre la norma legal interna ${ }^{53}$.

\section{LA SITUACIÓN DEL CONVENIO CHILENO ARGENTINO DE SEGURIDAD SOCIAL DE 1971, EN LA REGIÓN MAGALLÁNICA.}

El Convenio de Seguridad Social entre Chile y Argentina del año $1971^{54}$, fue el primero en ser celebrado por nuestro país, en forma bilateral, en materias de seguridad social, con un carácter general, es decir abarcando diversos regímenes de prestaciones de seguridad social ${ }^{55}$. Al mismo, le han sucedido numerosos otros tratados, especialmente a partir de $1990^{56}$.

52 Ibídem, p. 58.

53 Vid. la discusión del tema en: Medina Q., Cecilia y Mera F., Jorge (eds.), Sistema Jurídico y Derechos Humanos. El derecho nacional y las obligaciones internacionales de Chile en materia de Derechos Humanos, (Santiago, Cuadernos de Análisis Jurídico de la Universidad Diego Portales, 1996).

54 Vid. Subsecretaría de Previsión Social, op. cit. (nota 2).

55 El acuerdo más remoto que es citado en esta materia es aquél celebrado en 1819, entre el naciente Estado de Chile independiente y las Provincias del Río de la Plata, para beneficiar a los sargentos, cabos y soldados del Ejército de Los Andes, inutilizados en funciones de guerra desde la Batalla de Chacabuco, y que en lo sucesivo se inutilicen en defensa de aquél territorio. Vid. Santana Escobar, Jorge, Análisis del Convenio de Seguridad Social Chileno-Argentino de 1971 (Valparaíso, Memoria de Prueba, Escuela de Derecho Universidad Católica de Valparaíso, s.e., 1988), pág. 1.

56 Vid. Subsecretaría de Previsión Social, op. cit., nota 2. Entre tales Tratados, cabe mencionar los ratificados con Paraguay (1977), España (1980), Reino de Dinamarca (1995), Brasil (1996), Reino de los Países Bajos (1997), Suiza (1998), Reino de España (1998), Canadá (1998), Reino de Noruega (1998), Gran Ducado de Luxemburgo (1999), Reino de Bélgica (1999), República Oriental del Uruguay (1999), Austria (1999), Portugal (2000), Francia (2001), Estados Unidos de América (2001), República Checa (2004), Perú (2004), Australia (2004) y Venezuela (2005), a la par que numerosos Acuerdos complementarios. En cada caso, indico el año del Decreto de promulgación. Los textos respectivos en: http://www.bcn.cl 
A pesar de su trascendencia, el citado Convenio, suscrito en octubre de 1971, fue escasamente destacado en el contexto del dinámico y conflictivo escenario político chileno y latinoamericano de la época, y más aún no quedó establecida su vinculación con el contemporáneo desarrollo, en aquel momento, del Derecho Internacional en el ámbito de la Seguridad Social.

En efecto, según consta del propio texto del Convenio, su origen se encuentra en la llamada Declaración de Salta, formulada, meses antes, por los Presidentes de Chile y Argentina, en aquella ciudad transandina, el 24 de julio de 1971. En dicha Declaración, por cierto, tales altas autoridades manifestaban, entre otros aspectos de sus relaciones bilaterales, y luego de dar primera importancia a las de orden limítrofe, lo siguiente:

7.- Consideran que el factor humano reviste importancia fundamental en las relaciones entre los dos Estados. Los Presidentes comprueban con satisfacción los esfuerzos realizados para solucionar con espíritu de justicia social las situaciones provocadas por el desplazamiento de trabajadores temporales de un país a otro. Destacan que ambos Gobiernos han intercambiado proyectos de un convenio laboral y acuerdan que expertos de ambos países se reúnan en Buenos Aires el 23 de agosto próximo, a fin de resolver los aspectos técnicos de esta importante cuestión ${ }^{57}$.

La importante cuestión a que aludía la citada declaración, en una de sus últimos numerales, era aquella a que se refería el Convenio $\mathrm{N}^{\circ} 118$, de 28 de junio de 1962, de la OIT, ya citado, sobre Igualdad de Trato de nacionales y extranjeros en materias de seguridad social, y que no había sido ratificado por Chile ni Argentina, y que afectaba sobre todo a los numerosos trabajadores chilenos que, en diversas épocas, habían cruzado Los Andes o sólo la pampa patagónica, en busca de mejor suerte. Tales trabajadores, al regresar a Chile, no podían invocar para sus beneficios previsionales los tiempos cotizados en Argentina, ni viceversa ${ }^{58}$.

57 Vid. El Mercurio, 25 de julio de 1971, pág. 33.

58 Sobre las carasterísticas de estas poblaciones migratorias, véase: Martinic Beros, Mateo, "Contribución magallánica a la formación y desarrollo de la sociedad santacruceña: corrientes migratorias", en: Lacoste, Pablo (comp.), Argentina y Chile 500 años de integración, Revista de Estudios Transandinos, Mendoza, 1997, año I, № 1, pp. 197-204.
El Presidente de la República de Chile, en aquella época, don Salvador Allende, no podía menos que conocer tal importante cuestión, ya que había desempeñado el cargo de Senador por Magallanes hasta antes de su elección a la Primera Magistratura de la Nación, en $1970^{59}$.

En cambio, para su contraparte argentina, el Presidente de facto desde el 22 de marzo de 1971, General Alejandro Lanusse, el acercamiento con el Gobierno de Chile, del cual le separaban profundas diferencias ideológicas, obedecía a complejas razones estratégicas de equilibrio político con Brasil, propias de la ya influyente doctrina de la seguridad nacional ${ }^{60}$. Así lo reconoció el decano de la prensa chilena, al señalar en uno de sus editoriales que: $E l$ encuentro sostenido por los Presidentes de Chile y Argentina en la ciudad de Salta ha tenido como principal mérito reafirmar las relaciones históricas entre ambos países, por encima de las particulares orientaciones doctrinarias de los respectivos gobiernos ${ }^{61}$. Esta misma fuente, luego de analizar latamente los alcances de los Acuerdos de Salta, en cuanto a los problemas limítrofes, concluye señalando:

En el plano bilateral, la reunión de los señores Allende y Lanusse tendrá favorable repercusión en la evolución de la pacífica complementación chileno-argentina en aspectos tales como el aumento

59 Por cierto, antes de su viaje a Salta, el Presidente Allende se había referido al tema previsonal. Así, fuentes periodísticas señalaban sus dichos en la siguiente forma: diversas cosas en común que nos unen a la Argentina (...) como ejemplo, la idea de respetar los derechos previsionales de los ciudadanos que trabajen en uno u otro país. Vid.: El Mercurio, 6 de julio de 1971, pág. 19.

60 Ello es destacado por la crónica de El Mercurio que, citando el periódico argentino La Opinión, señalaba: En el intervalo que va desde la última reunión de cancilleres de la cuenca del Plata, en Asunción del Paraguay, a comienzos de junio hasta el 12 de julio, Argentina firmó acuerdos con Paraguay, Chile, Uruguay y Bolivia sobre el aprovechamiento de los ríos internacionales que respaldan su posición dentro de la cuenca en torno a ese problema, enfrentada a la brasileña, recordaron las fuentes diplomáticas. Más adelante agrega: el objetivo aparente-según fuentes diplomáticas- es dejar (aislado a) Brasil, al menos en su posición jurídica, que sostiene la soberanía irrestricta sobre los tramos nacionales de los ríos internacionales, y además la ejerce construyendo varias represas hidroeléctricas, en especial sobre el río Paraná (El Mercurio, 24 de julio de 1971, pág. 31).

61 Vide El Mercurio, editorial de 26 de julio de 1971, El espíritu de los Acuerdos de Salta, página 21. 
del comercio recíproco, la complementación de la industria automotriz, la integración física, la unión vial y los puertos francos (sic) ${ }^{62}$.

Así, el aspecto previsional en beneficio de los trabajadores es completamente omitido en la enumeración de las favorables repercusiones de los Acuerdos de Salta.

Empero, luego de breves meses de estudio, finalmente el Convenio fue efectivamente suscrito, junto con un acuerdo en materia laboral, en la ciudad de Antofagasta, el 17 de octubre de 1971, por los Cancilleres de Chile, Clodomiro Almeyda Medina, y de Argentina, Luis María de Pablo Pardo, como plenipotenciarios designados por los respectivos Jefes de Estado, reunidos en la misma ciudad. En este caso, el editorial del señalado periódico pudo decir:

Siguiendo la línea de franca colaboración entre ambas naciones, los Presidentes Lanusse y Allende firmaron dos convenios internacionales destinados a resolver un antiguo problema que afecta particularmente a Chile. Por muchos años se había procurado convenir un estatuto que permitiera el trato justo de los trabajadores chilenos $y$ argentinos, que se avecinan en la otra república hermana. Sólo ahora ha podido firmarse un convenio laboral y uno previsional que contemplan las situaciones de los trabajadores que prestan sus servicios en el territorio trasandino. Como es sabido, son muchos miles de chilenos los que emigran definitiva o temporalmente a la Argentina. Todos ellos se beneficiarán con el nuevo estatuto ${ }^{63}$.

Por su parte, el Canciller Almeyda declaraba: en obedecimiento a lo dispuesto en la histórica declaración de Salta, de julio último, nuestros dos Gobiernos han dado cima a través de estos Convenios en sólo dos meses, a negociaciones que han durado largos 18 años, satisfaciendo por fin una urgente, justa y sentida aspiración de un importante sector de nuestros hombres de trabajo $^{64}$. Esta afirmación demuestra la importancia asignada al Convenio, como también la circunstancia de ser el resultado de un largo proceso de gestación -18 años-, cuyo impulso político definitivo se logra por el gobierno del Presidente Allende. Por lo demás, esto explica también la celeridad en la aprobación del Convenio

62 Ibídem.

63 El Mercurio, editorial del 19 de octubre de 1971, Frutos de la Entrevista de Antofagasta, pág. 3.

64 El Mercurio, 18 de octubre de 1971, pág. 25. por el Congreso Nacional de Chile, la que es obtenida en los primeros meses de 1972, permitiendo su promulgación el 12 de abril de ese año ${ }^{65}$.

Con todo, más allá de las circunstancias políticas internas e internacionales que rodearon la celebración del Convenio de 1971, cabe tener presente que la reforma constitucional aprobada por Ley 17.398, de 9 de enero de 1971, conocida como Estatuto de Garantías, había introducido en forma expresa la garantía al derecho a la seguridad social, en el numeral 16, del artículo 10, de la Constitución Política de 1925, lo que daba un claro sustento dogmático constitucional a la aprobación del Convenio.

Las auspiciosas proyecciones de la celebración de los citados Convenios, en especial el de Seguridad Social, fue, no obstante, desmentida de modo importante en los hechos ${ }^{66}$.

En efecto, el Convenio de 1971 ha tenido una aplicación más bien escasa en la Región Magallánica, la que no se compadece con los principios antes enunciados del moderno Derecho Internacional de los Derechos Humanos en materias de Seguridad Social. Por cierto, tanto las disposiciones del propio

65 Vid. ut supra (nota 2). El periódico El Magallanes, de Punta Arenas, dedicó al tema su editorial del 21 de octubre de 1971, bajo el epígrafe Entrevistas históricas, aludiendo a los Convenios Laboral y de Seguridad Social, como magníficos antecedentes. Vid. pp. 3 y 5 , en ésta reproduce íntegro el último Convenio.

66 En una nota editorial de El Mercurio, del 21 de octubre de 1971, se realiza un breve análisis del alcance del Convenio: Mucho se ha discutido sobre cuál es el número exacto de los obreros chilenos en la Patagonia. Algunos hacen subir la cifra a 300 mil personas y otros a 200 mil. El cálculo es difícil porque muchos de los más antiguos residentes se han casado con argentinas y han adquirido la nacionalidad argentina. Además es muy difícil el recuento de los obreros de temporadas que entran y salen de territorio argentino en épocas de cosechas o de esquila como, igualmente, no pueden ser censados los obreros furtivos que pasan la frontera sin el debido control de las autoridades policiales o administrativas. En todo caso, el número de trabajadores chilenos es muy importante, señalándose como uno de sus principales centros de actividades las minas de carbón de Río Turbio, la industria petrolera de Comodoro Rivadavia y en muy diversas actividades en las ciudades de Bariloche, Río Gallegos, Río Grande y Ushuaia. Igualmente, las zonas agrícolas y frutícolas de la Provincia de Río Negro y los trabajos de campo en las estancia". Luego de esta dramática descripción, el editorial concluye: Aún cuando los dos Convenios se aplican tanto a trabajadores chilenos como argentinos, serán los primeros los más favorecidos porque su número supera en mucho a los segundos (pág. 3) 
Convenio como la aplicación práctica del mismo han limitado su eficacia y alcance como real instrumento de protección del derecho a la seguridad social ${ }^{67}$.

En cuanto a las disposiciones del Convenio ${ }^{68}$, y en relación al régimen chileno, aquél reconoce sólo los beneficios previsionales de algunas de las antiguas Cajas de Previsión existentes en su época, como el Servicio de Seguro Social, la Caja de Previsión de los Empleados Particulares (Empart), y el régimen general de Empleados Públicos, pero no de todas las restantes Cajas, posteriormente fusionadas en el denominado Instituto de Normalización Provisional (INP), en virtud de la Ley 18.689, y menos aún los beneficios del Sistema Privado de Pensiones, establecido en Chile por el Decreto Ley № 3.500 , de 1980. Esto último obligó a la celebración de un nuevo Convenio Internacional, suscrito en la ciudad de Buenos Aires, el 26 de abril de 1996, para regular la situación de los beneficios derivados del nuevo sistema de pensiones, consagrado en Chile por el referido Decreto Ley, a través de las Administradoras de Fondos de Pensiones (AFP), que era completamente extraño al anterior Convenio de 1971. Este nuevo Convenio, empero, aún no entra en vigencia, puesto que está pendiente su ratificación.

Del mismo modo, en la medida que el Convenio de 1971, que continúa vigente, sólo regula pensiones previsionales, resulta discutible su aplicación respecto de ciertos beneficios no contributivos, como aquellos consagrados en Chile por la Ley 19.234, sobre Exonerados Políticos, que obviamente no pudo tener en vista ${ }^{69}$.

Por otra parte, la concurrencia de la República Argentina en el pago de sus cuotas proporcionales de acuerdo al Convenio vigente, ha sido extremadamente lenta, a tal grado que, según datos aportados al autor por la Agencia del INP de Punta Arenas, al mes de marzo de 2007 existían más de 30 solicitudes pendientes de pensionados en Chile que aguardaban

67 Cfr. Bandieri, Susana (coord.), Cruzando la Cordillera...La frontera argentino-chilena como espacio social, ( Neuquén, Centro de Estudios de Historia Regional, 2001).

68 Sobre las disposiciones del Convenio, véase: Blanco Lobos, Gonzalo y Alviz Riffo, Christian, Análisis general del contenido de los Convenios Internacionales de Seguridad Social suscritos por Chile con otros Estados (Santiago, Memoria de Prueba, Facultad de Derecho Universidad de Chile, s.e., 2001)

69 Publicada en el D. Of. de 12 de agosto de 1993, fue modificada por las leyes 19.350, 19.582 y 19.881 . el pago de la cuota argentina. Pero, a la vez, y aquí está lo más delicado, en los últimos 10 años, menos de cinco beneficiarios de la región habían obtenido el pago de esa cuota o parte.

Por cierto, cabe destacar que los beneficiarios potenciales del Convenio se estimaban en cerca de 300.000, al año 2001. Sin embargo, a esa misma fecha, y luego de 30 años de su vigencia, se habían concedido sólo 299 beneficios, y comprometido el segundo mayor aporte anual al año 2005, luego de España, en el financiamiento de distintos beneficios, por un total de 174,535 millones de pesos ${ }^{70}$.

\section{CONCLUSIONES}

El moderno Derecho Internacional de los Derechos Humanos, en materia de Seguridad Social, impone al Estado la obligación de asumir un rol activo en la protección de tales derechos, debiendo adecuar sus normas e instituciones, que le vinculan con los supuestos del Estado neoliberal, que fue introducido deliberadamente en nuestro ordenamiento jurídico como parte de una determinada concepción ideológica que ya no guarda relación con las características de la sociedad, la economía, la cultura y la tecnología en el mundo contemporáneo, y que tampoco protege adecuadamente los derechos de las personas.

Por otra parte, la práctica del Estado contemporáneo debe estar inspirada en la noción de Derechos Humanos, tanto a nivel nacional como internacional. Pero, además, ella no basta si no está acompañada de una cultura de respeto a los Derechos Humanos, propia de la sociedad, y que requiere de un cambio de la mayor trascendencia individual y supranacional.

En esta perspectiva, en el caso chileno, resulta preocupante que el Informe del Consejo Asesor Presidencial para la reforma del Sistema Previsional, publicado en el mes de julio de 2006, no contenga ninguna referencia explícita a la situación de los beneficiarios del Convenio del año 1971, tanto más cuanto que, al definir la Pensión Básica Universal (PBU), que pretende ser la base del pilar solidario del nuevo sistema, se señala que ella es otorgada para

70 Cfr. Blanco, Gonzalo y Alviz, Christian, op. cit. (nota 68), págs. 120 y 121. Al año 2005, la cifra era de 396 beneficios; vid. en: http://www.inp.cl/portal/Documentos/ Anuario_2005/pdfs/ae05_c200.pdf 
las personas que no obtengan ninguna pensión autofinanciada del sistema contributivo ${ }^{71}$. Pues bien, resulta que las pensiones obtenidas conforme al citado Convenio, son pensiones autofinanciadas, aunque pagadas en cuotas proporcionales por cada Estado comprometido. El problema que se plantea es si acaso la PBU, aún en la proporción que se mantiene a pesar del autofinanciamiento del propio cotizante, es aplicable en el caso de la cuota proporcional de los beneficios previsionales de cargo de Argentina, sin que ello signifique la obligación de reintegrar, por el beneficiario, una vez que se pague la cuota o parte de este último Estado ${ }^{72}$.

Por último, es posible que al Convenio de octubre de 1971 le faltara sustento teórico suficiente, en relación al contemporáneo desarrollo en su época del Derecho Internacional de los Derechos Humanos, y por eso su importancia fuera superada por la magnitud de los vertiginosos acontecimientos políticos que se sucedieron aquél año ${ }^{73}$.

Por lo demás, la revisión comparativa del Convenio de 1971 con los nuevos Convenios suscritos por Chile con posterioridad a 1990, demuestran la mayor complejidad y elaboración conceptual que presentan éstos últimos, protegiendo de manera más adecuada los derechos de los beneficiarios ${ }^{74}$.

71 El texto puede consultarse en: $h t t p: / / w w w . e m o l . c o m / n o t i c i a s /$ documentos/pdfs/resumen_ejecutivo.pdf

72 Desde luego, cabe observar que el Proyecto de ley de reforma previsional, ingresado en el Congreso chileno, el 19 de diciembre de 2006, no contempla esta situación. Por el contrario, los requisitos para acceder a la PBU, según el Mensaje Presidencial № 558-354, son; ...en régimen, hombres y mujeres, a los 65 años de edad, que pertenezcan a los tres primeros quintiles de ingreso (es decir, el 60\% de la población de menores ingresos) y reúnan un período mínimo de 20 años de permanencia en el país, y de 4 de los últimos 5 años previos a la solicitud del beneficio (pág. 9). Vid. Boletín № 4742-13, art. 3, letra c), en: http://www. bcn.cl

73 Por cierto, la falta de vinculación normativa entre el Convenio de 1971 y el Derecho Internacional sobre Derechos Humanos, particularmente el Pacto Internacional de Derechos Económicos, Sociales y Culturales, adoptado por la ONU, el 19 de diciembre de 1966, queda en evidencia al comprobar que este último Pacto fue suscrito por Chile el 16 de septiembre de 1969, ratificado el 10 de febrero de 1972 , pero recién promulgado por D.S. N ${ }^{\circ} 326$ de RREE, de 28 de abril de 1989, y publicado en el D. Of. de 27 de mayo del mismo año.
A pesar de todo ello, es posible sostener, sin embargo, que el Convenio fue quizás la respuesta impulsada por el Gobierno chileno, en 1971, para favorecer a los chilenos y chilenas de la Trapananda y la Patagonia, abandonados en la inmensidad de las pampas trasandinas, que durante mucho tiempo demandaban no sólo por el respeto de sus derechos previsionales, sino por su efectiva pertenencia a la comunidad nacional, más allá de encontrarse en suelo extranjero. Desde luego, cabe destacar que, por parte de Chile, ha habido un esfuerzo serio de dar cumplimiento al Convenio ${ }^{75}$. No obstante, es lamentable constatar las dificultades que ha debido enfrentar su contraparte, cuyos motivos para celebrar ese acuerdo, como hemos visto, eran muy distintos a los que animaban a las autoridades chilenas.

Con todo, cabe admitir, también como hipótesis, que la escasa aplicación del Convenio de 1971, pueda deberse a las precarias condiciones de contratación de los trabajadores chilenos en Argentina, quienes, junto con la carencia de una cultura previsional fuerte, debieron además competir en desventaja con los propios trabajadores argentinos, incluso a veces bajo clandestinidad, y ello redundó en la ausencia de tiempos de cotización que pudieran ser impetrados conforme al Convenio ${ }^{76}$.

La demanda de esos chilenos en territorio extranjero, por tanto, aún reclama de una respuesta adecuada, que es posible esperar mediante la agilización de los trámites correspondientes a los beneficios del antiguo Convenio de 1971, gracias a los esfuerzos de integración desarrollados en los últimos años ${ }^{77}$, como también mediante la definitiva ratificación, por ambas repúblicas, del nuevo Convenio de 1996.

74 Ver, por ejemplo, el Convenio de Seguridad Social, suscrito con Francia, de fecha 25 de junio de 1999, ratificado por D.S. № 430 , de 3 de julio de 2001, y publicado en el Diario Oficial de 8 de septiembre de 2001.

75 En el mismo sentido, el Acuerdo Administrativo complementario para la aplicación del Convenio de 1971 , suscrito en Buenos Aires, el 26 de abril de 1996, y ratificado por D.S. № 634, de fecha 9 de mayo de 1996, publicado en el D. Oficial de 20 de julio de 1996, que simplifica la contabilización de períodos de afiliación.

76 Vid. Scher, Ofelia Beatriz, "Inmigración limítrofe a la República Argentina. Una aproximación al caso chileno. 1950-1990", en: Lacoste, Pablo (comp.), op. cit. (nota 58), pp. 205-221.

77 Cfr. Lacoste, op. cit. (nota 58).

(Fuentes y bibliografía citada en el texto. Las referencias a sitios de consulta vía internet, han sido comprobadas al 26 de julio de 2007). 
